Article

\title{
A Cd(II) Coordination Polymer Based on Mixed Ligands: Synthesis, Crystal Structure, and Properties
}

\author{
Shuai-Shuai Han, Zi-Wei He, Lei Li and Shui-Sheng Chen *(D) \\ College of Chemistry and Chemical Engineering, Fuyang Normal University, Fuyang 236041, China; \\ fyuvssh2019@163.com (S.-S.H.); heziwei_hzw@yeah.net (Z.-W.H.); ansfylei2017@163.com (L.L.) \\ * Correspondence: fyuniv@163.com
}

Received: 11 November 2019; Accepted: 25 November 2019; Published: 27 November 2019

\begin{abstract}
A new coordination polymer, namely, $\left[\mathrm{Cd}(\mathrm{L})(\mathrm{frda})\left(\mathrm{H}_{2} \mathrm{O}\right)\right] \cdot 0.5 \mathrm{~L} \cdot \mathrm{H}_{2} \mathrm{O}(\mathbf{1})$ was synthesized by hydrothermal reaction based on mixed multi-N donor 1-(4-(1H-imidazol-5-yl) phenyl)-1H1,2,4-triazole $(\mathrm{L})$ and $\mathrm{O}$-donor 2,5-furandicarboxylic acid ligands $\left(\mathrm{H}_{2} \mathrm{frda}\right)$ with $\mathrm{CdCl}_{2} \cdot 2 \cdot 5 \mathrm{H}_{2} \mathrm{O}$. Compound 1 was characterized by single-crystal $x$-ray diffraction, elemental analysis, and IR spectroscopy. In 1, both the multi-N donor and O-donor frda ${ }^{2-}$ ligands act as linear two-connectors to bridge $\mathrm{Cd}$ (II) atoms, forming a two-dimensional (2D) layer. Interestingly, the parallel 2D layers stack in an AAA $\cdots$ mode, and the infinite one-dimensional (1D) channels formed along the $a$-axis direction, where the uncoordinated L molecules were embedded in the void. Furthermore, the weak interactions including the rich hydrogen bonding and $\pi-\pi$ stacking interactions progress the $2 \mathrm{D}$ structure into a three-dimensional (3D) supramolecular polymer. Diffuse reflectance spectra and the luminescent property were also investigated.
\end{abstract}

Keywords: coordination polymer; characterization; optical property

\section{Introduction}

Coordination polymers (CPs) consisting of organic ligands and metal ions have attracted an upsurge in research during the past decades, due to their charming structures and their possibly applied domain of luminescence [1-4], gas adsorption/separation [5,6], proton conductivity [7], chemical separations [8], catalysis [9], and so on. Generally speaking, organic ligands act as linkers while metal ions act as connectors, and therefore, their orientation of the interacting sites for ligands and coordination numbers for metal ions, respectively, are the most fundamental two factors to decide the framework and properties of CPs [10-13]. In addition to these two core factors, other conditions such as the ligand-metal ratio, reaction solvent, template, $\mathrm{pH}$ value, and counteranion also have effects on the resulting structure $[14,15]$. Essentially, multidentate organic ligands with definite linking coordination sites result in the spatial arrangement for metal connectors in the final framework. Several important factors such as the length of organic ligands, their flexibility/ rigidity, decorated functional groups, varied coordination modes, or substituent groups of organic ligands have substantial effects on the resulting frameworks of CPs $[16,17]$. Therefore, the design and synthesis for organic compounds are key jobs to construct desirable CPs with specific structures, topologies, and functionalities. In this context, the effective 'reticular synthesis' put forward by Yaghi et al. was confirmed to be the most effective method to direct the assembly of desired frameworks with rigid organic linkers [18]. However, the flexible ligands are an important part in the assembly of interpenetrated structure by adopting fickle conformations and geometries via rotating, bending, or twisting transformation $[19,20]$ because these flexible backbones often facilitate the stabilization of the framework through interpenetration to avoid the void within the structure. Generally speaking, the multi-N donor and O-donor carboxylic acids are two types of extensively used ligands because of their diverse coordination abilities [21,22]. For 
example, $\mathrm{N}$-donor polyazaheteroaromatic organic molecules are often used to form multipodal anions employed as chelating, bridging, and also acting as charge balance anionic building units for assembling polynuclear species. In our previous work, we deliberately designed a series of 4-imidazoly-containing organic molecules such as 1,3,5-tri(1H-imidazol-4-yl)benzene and 1,4-di(1H-imidazol-4-yl)benzene, which have been successfully employed to build metal-imidazolate CPs with favorable gas adsorption properties for $\mathrm{CO}_{2}$ gas [23-25]. Apart from the polyazaheteroaromatic linkers, the aromatic polycarboxylate compounds are another kind of important O-donor ligands due to their diverse coordination modes for carboxyl groups, which can display chelating, mono/bis-bridging modes. Due to their good bridging abilities, a high connector of polynuclear metal centers can easily be formed, which can be employed to build higher node frameworks. Interestingly, we employed the mixed 4-imidazoly-containing ligands and various carboxylic acids to build diverse frameworks including cage structure, one-dimensional tube chain, two-dimensional layer structures, and three-dimensional interpenetrating and non-interpenetrating structures with different topologies, because the N-donor ligands can effectively adjust the coordination modes of polycarboxylate acids [26-28]. By virtue of their suitable adjustability for the mixed polyazaheteroaromatic and carboxylic ligands, we synthesized the multi-N donor ligand 1-(4-(1H-imidazol-5-yl)phenyl)-1H-1,2,4-triazole (L) (see Supplementary Materials), together with O-donor 2,5-furandicarboxylic acid ligand $\left(\mathrm{H}_{2}\right.$ frda) to react with $\mathrm{CdCl}_{2} \cdot 2.5 \mathrm{H}_{2} \mathrm{O}$, and obtained a new $\mathrm{Cd}(\mathrm{II})$ coordination polymer $\left[\mathrm{Cd}(\mathrm{L})(\mathrm{frda})\left(\mathrm{H}_{2} \mathrm{O}\right)\right] \cdot 0.5 \mathrm{~L} \cdot \mathrm{H}_{2} \mathrm{O}(\mathbf{1})$ as a continual work. The diffuse reflectance spectra and luminescent property of $\mathbf{1}$ were also investigated.

\section{Experimental Section}

\subsection{Materials and Instrumentation}

The chemicals in this experiment were of reagent grade. The 1-(4-(1H-imidazol-5-yl) phenyl)-1H1,2,4-triazole organic molecule was synthesized according to the related literature [29]. Infrared spectra was executed on a FT-IR spectrophotometer (Instrument Inc., Karlsruhe, Germany) using KBr pellets. Elemental analyses were analyzed on a Perkin-Elmer 240C Elemental Analyzer (PerkinElmer, Waltham, USA). Photoluminescence spectra were used with a HORIBA FluoroMax-4 (Edinburgh Instruments, Edinburgh, UK).

\subsection{Synthesis of $\left[\mathrm{Cd}(\mathrm{L})(\mathrm{frda})\left(\mathrm{H}_{2} \mathrm{O}\right)\right] \cdot 0.5 \mathrm{~L} \cdot \mathrm{H}_{2} \mathrm{O}(1)$}

A mixture of $\mathrm{L}(0.042 \mathrm{~g}, 0.2 \mathrm{mmol}), \mathrm{H}_{2}$ frda $(0.032 \mathrm{~g}, 0.2 \mathrm{mmol}), \mathrm{CdCl}_{2} \cdot 2.5 \mathrm{H}_{2} \mathrm{O}(0.0456 \mathrm{~g}, 0.2 \mathrm{mmol})$, and $\mathrm{NaOH}(0.016 \mathrm{~g}, 0.4 \mathrm{mmol})$ in $8 \mathrm{~mL} \mathrm{H} \mathrm{H}_{2} \mathrm{O}$ was sealed in a Pyrex bottle $(16 \mathrm{~mL})$ and heated at $120^{\circ} \mathrm{C}$ for $48 \mathrm{~h}$. Colorless block crystals of 1 were isolated by filtration, with a yield of $68 \%$. Anal. Calcd. (\%) for $\mathrm{C}_{22} \mathrm{H}_{16} \mathrm{~N}_{8} \mathrm{O}_{7} \mathrm{Cd}: \mathrm{C}, 47.30 ; \mathrm{H}, 3.26 ; \mathrm{N}, 18.39$. Found (\%): C, 47.16; H, 3.19; N, 18.48. IR(KBr): 3700-3050(s), 1581(m), 1399(m), 1373(m), 1278(w), 1158(w), 1066(m), 977(w), 837(w), 818(w), 786(w), 669(w), 636(w), 577(w), 487(w) $\mathrm{cm}^{-1}$.

\subsection{Crystal Structure Determination}

The single crystal data of $\left[\mathrm{Cd}(\mathrm{L})(\mathrm{frda})\left(\mathrm{H}_{2} \mathrm{O}\right)\right] \cdot 0.5 \mathrm{~L} \cdot \mathrm{H}_{2} \mathrm{O}(\mathbf{1})$ suitable for analysis were selected and collected on a Rikaku XtaLAB Synergy diffractometer. The structure was solved and refined using the OLEX2 program suite, equipped with the ShelXT and ShelXL program [30]. The crystallographic refine data are displayed in Table 1. 
Table 1. Crystallographic data and structure refinement for CP 1.

\begin{tabular}{|c|c|}
\hline Empirical Formula & $\mathrm{C}_{45} \mathrm{H}_{39} \mathrm{~N}_{15} \mathrm{O}_{14} \mathrm{Cd}_{2}$ \\
\hline Formula weight & 1238.73 \\
\hline Temperature/K & $293(2)$ \\
\hline Crystal system & Triclinic \\
\hline Space group & $P-1$ \\
\hline$a / \AA$ & $10.0552(2)$ \\
\hline$b / \AA$ & $10.1437(2)$ \\
\hline$c / \AA$ & $14.1937(2)$ \\
\hline$\alpha /^{\circ}$ & $75.690(10)$ \\
\hline$\beta /{ }^{\circ}$ & $69.664(2)$ \\
\hline$\gamma /^{\circ}$ & $62.167(2)$ \\
\hline Volume $/ \AA^{3}$ & 1194.13(4) \\
\hline Z & 1 \\
\hline$\rho_{\text {calc }} \mathrm{mg} / \mathrm{mm}^{3}$ & 1.723 \\
\hline$\mu / \mathrm{mm}^{-1}$ & 0.976 \\
\hline$F(000)$ & 622 \\
\hline Index ranges & $\begin{array}{l}-12 \leq h \leq 13 \\
-12 \leq k \leq 12 \\
-13 \leq l \leq 18\end{array}$ \\
\hline Reflections collected & 14832 \\
\hline Independent reflections & 4980 \\
\hline Data/restraints/parameters & $5560 / 0 / 396$ \\
\hline Goodness-of-fit on $F^{2}$ & 1.030 \\
\hline Final $R$ indexes $[I \geq 2 \sigma(I)]$ & $R_{1}=0.0310, w R_{2}=0.0709$ \\
\hline Final $R$ indexes [all data] & $R_{1}=0.0361, w R_{2}=0.0742$ \\
\hline Largest diff. peak/hole / e $\AA^{-3}$ & $0.470 /-0.460$ \\
\hline
\end{tabular}

The CCDC number is 1957742 for 1, deposited with the Cambridge Crystallographic Data Center. The data can be obtained on application to the CCDC, 12 Union Road, Cambridge CB2 1EZ, UK.

\section{Results and Discussion}

\subsection{Structural of $\left[\mathrm{Cd}(\mathrm{L})(f r d a)\left(\mathrm{H}_{2} \mathrm{O}\right)\right] \cdot 0.5 \mathrm{~L} \cdot \mathrm{H}_{2} \mathrm{O}(1)$}

X-ray crystallographic analysis shows that CP 1 crystallizes in the triclinic $P_{1^{-}}$space group (Table 1), and the asymmetric unit of $\mathbf{1}$ contains one unique $\mathrm{Cd}(\mathrm{II})$ atom, one coordinated $\mathrm{L}$ organic ligand, one deprotonated frda ${ }^{2-}$ molecule, one coordinated water molecule, a half of uncoordinated $\mathrm{L}$ ligand, and one lattice water molecule. The unsymmetrical polyazaheteroaromatic ligand of N2 and $\mathrm{C} 8, \mathrm{~N} 5$ and $\mathrm{C} 7$, and $\mathrm{N} 4$ and $\mathrm{C} 10$ atoms can be defined according to their different atomic displacement parameters. The lattice of $\mathrm{L}$ lies an inversion center. The center $\mathrm{Cd}(\mathrm{II})$ atom is linked by two nitrogen atoms ( $\mathrm{N} 1$ and $\mathrm{N} 3 \mathrm{~A})$ from two different $\mathrm{L}$ ligands and four oxygen atoms $(\mathrm{O} 1, \mathrm{O} 2$, and $\mathrm{O} 3 \mathrm{~B}, \mathrm{O} 4 \mathrm{~B})$ from two pairs of carboxyl groups and one oxygen atom $(\mathrm{O} 6)$ from the coordinated water ligand, thereby forming a seven-coordinated coordination geometry with a $\mathrm{N}_{2} \mathrm{O}_{5}$ donor set (Figure 1). The $\mathrm{Cd}-\mathrm{O}$ bond lengths varied from 2.346(2) to 2.5866(18) $\AA$ and the $\mathrm{Cd}-\mathrm{N}$ ones were 2.281(2) and 2.288(2) $\AA$ (Table 2), and the coordination angles were around the Cd1 range from 52.90(6) to $175.41(7)^{\circ}$. The $\mathrm{L}$ ligands adopt linear bidentate bridging mode to combine $\mathrm{Cd}(\mathrm{II})$ ions to form one-dimensional (1D) chains. The adjacent $1 \mathrm{D}$ chains are connected by frda ${ }^{2-}$ ligands to form a two-dimensional (2D) layer (Figure 2). From a topological perspective, the 2D layers can be simplified to 4-connected sql nets with point symbol $\left(4^{4} \cdot 6^{2}\right)$. The parallel 2D layers are stacked in an AAA $\cdots$ mode, and the infinite 1D channels are created along the $a$-axis, where the uncoordinated L molecules are embedded in the void of 1 (Figure 3). The solvent-accessible volume of these channels without considering guest $\mathrm{L}$ molecules was estimated to be $387.8 \mathrm{~A}^{3}$, approximately $32.5 \%$ of the total crystal volume of $1194.1 \mathrm{~A}^{3}$, calculated with the PLATON program [31]. It is noteworthy that the nitrogen and oxygen atoms from multi-N donor or carboxyl groups, can easily be employed as acceptors of hydrogen bonding, and as a return, the weak interaction can easily benefit the formation of a supramolecular polymer. In the packing diagram, 
rich hydrogen bonding interaction are found in $\mathrm{CP} \mathbf{1}$, and the $\mathrm{C}-\mathrm{H} \cdots \mathrm{O}, \mathrm{O}-\mathrm{H} \cdots \mathrm{O}$ hydrogen bonding including $\left(\mathrm{C}(2) \cdots \mathrm{O}(2)^{\mathrm{c}} 3.142(3) \AA, \mathrm{C}(2)-\mathrm{H}(2) \cdots \mathrm{O}(2) 148^{\circ} ; \mathrm{C}(10) \cdots \mathrm{O}(2)^{\mathrm{c}} 3.101(4) \AA, \mathrm{C}(10)-\mathrm{H}(10) \cdots \mathrm{O}(2)\right.$ $155^{\circ} ; \mathrm{C}(11) \cdots \mathrm{O}(6) 3.410(4) \AA, \mathrm{C}(11)-\mathrm{H}(11) \cdots \mathrm{O}(6) 151^{\circ} ; \mathrm{C}(6) \cdots \mathrm{O}(6) 2.738(3) \AA, \mathrm{C}(6)-\mathrm{H}(6 \mathrm{~B}) \cdots \mathrm{O}(6) 169^{\circ}$; $\left.\mathrm{O}(6) \cdots \mathrm{O}(5) 2.872(4) \AA, \mathrm{O}(6)-\mathrm{H}(6 \mathrm{~A}) \cdots \mathrm{O}(5) 167^{\circ} ; \mathrm{C}(9) \cdots \mathrm{O}(4) 3.086(3) \AA, \mathrm{C}(9)-\mathrm{H}(9) \cdots \mathrm{O}(4) 118^{\circ}\right)$ exist among the adjacent $2 \mathrm{D}$ layers (Table 3 ). In addition to the rich hydrogen bonding, classic weak $\pi-\pi$ stacking interactions could also be found between the neighboring 2D packing layers. The five-membered furan rings of the frda ${ }^{2-}$ ligands were completely parallel with the centroid-centroid distance of $3.49 \AA$, indicating the existence of strong $\pi-\pi$ stacking interactions [32,33]. On the whole, the weak interactions including the hydrogen bonding and $\pi-\pi$ stacking interactions progress adjacent $2 \mathrm{D}$ layers into a three-dimensional (3D) supramolecular polymer (Figure 4).

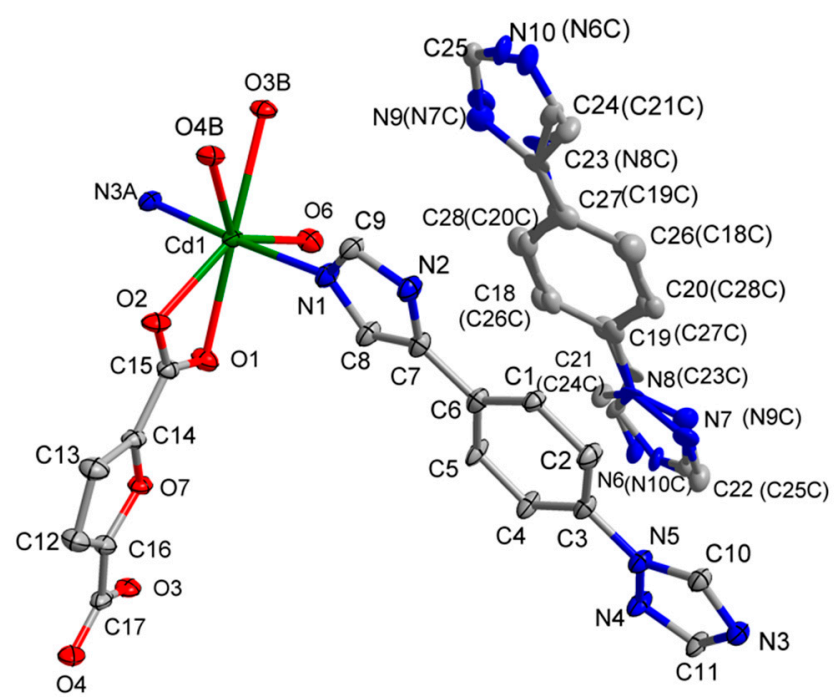

Figure 1. The coordination environment of Cd(II) ion and free L ligand in 1 . Symmetry code: A $x, y, 1+$ $z, \mathrm{~B} x, 1+y, z, \mathrm{C} 1-x, 2-y, 1-z$.

Table 2. Selected bond lengths $(\AA)$ and bond angles $\left({ }^{\circ}\right)$ for CP 1.

\begin{tabular}{|c|c|c|c|}
\hline Bond & $d$ & Bond & $d$ \\
\hline $\mathrm{Cd}(1)-\mathrm{N}(1)$ & $2.288(2)$ & $\mathrm{Cd}(1)-\mathrm{N}(3)^{\mathrm{i}}$ & $2.281(2)$ \\
\hline $\mathrm{Cd}(1)-\mathrm{O}(6)$ & $2.346(2)$ & $\mathrm{Cd}(1)-\mathrm{O}(2)$ & $2.3470(16)$ \\
\hline $\mathrm{Cd}(1)-\mathrm{O}(4) \mathrm{ii}$ & $2.3871(19)$ & $\mathrm{Cd}(1)-\mathrm{O}(3)$ ii & $2.5427(18)$ \\
\hline $\mathrm{Cd}(1)-\mathrm{O}(1)$ & $2.5866(18)$ & & \\
\hline Angle & $\omega$ & Angle & $\omega$ \\
\hline $\mathrm{N}(3){ }^{\mathrm{i}}-\mathrm{Cd}(1)-\mathrm{N}(1)$ & $175.41(7)$ & $\mathrm{N}(3){ }^{\mathrm{i}}-\mathrm{Cd}(1)-\mathrm{O}(6)$ & $90.86(8)$ \\
\hline $\mathrm{N}(1)-\mathrm{Cd}(1)-\mathrm{O}(6)$ & $84.94(8)$ & $\mathrm{N}(3)^{\mathrm{i}}-\mathrm{Cd}(1)-\mathrm{O}(2)$ & $93.45(6)$ \\
\hline $\mathrm{N}(1)-\mathrm{Cd}(1)-\mathrm{O}(2)$ & $90.84(7)$ & $\mathrm{O}(6)-\mathrm{Cd}(1)-\mathrm{O}(2)$ & $135.86(7)$ \\
\hline 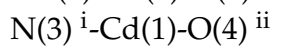 & $99.08(7)$ & $\mathrm{N}(1)-\mathrm{Cd}(1)-\mathrm{O}(4){ }^{\mathrm{ii}}$ & $82.57(7)$ \\
\hline $\mathrm{O}(6)-\mathrm{Cd}(1)-\mathrm{O}(4){ }^{\mathrm{ii}}$ & $133.33(7)$ & $\mathrm{O}(2)-\mathrm{Cd}(1)-\mathrm{O}(4){ }^{\mathrm{ii}}$ & $89.19(6)$ \\
\hline 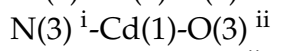 & $83.11(7)$ & $\mathrm{N}(1)-\mathrm{Cd}(1)-\mathrm{O}(3){ }^{\mathrm{ii}}$ & $94.58(7)$ \\
\hline $\mathrm{O}(6)-\mathrm{Cd}(1)-\mathrm{O}(3)^{\mathrm{ii}}$ & $83.62(7)$ & $\mathrm{O}(2)-\mathrm{Cd}(1)-\mathrm{O}(3)^{\mathrm{ii}}$ & $140.50(6)$ \\
\hline $\mathrm{O}(4)^{\mathrm{ii}}-\mathrm{Cd}(1)-\mathrm{O}(3)^{\mathrm{ii}}$ & $53.03(6)$ & $\mathrm{N}(3){ }^{\mathrm{i}}-\mathrm{Cd}(1)-\mathrm{O}(1)$ & 87.07(7) \\
\hline $\mathrm{N}(1)-\mathrm{Cd}(1)-\mathrm{O}(1)$ & $94.26(7)$ & $\mathrm{O}(6)-\mathrm{Cd}(1)-\mathrm{O}(1)$ & $83.57(7)$ \\
\hline $\mathrm{O}(2)-\mathrm{Cd}(1)-\mathrm{O}(1)$ & $52.90(6)$ & $\mathrm{O}(4){ }^{\mathrm{ii}}-\mathrm{Cd}(1)-\mathrm{O}(1)$ & $142.01(6)$ \\
\hline $\mathrm{O}(3){ }^{\mathrm{ii}}-\mathrm{Cd}(1)-\mathrm{O}(1)$ & $163.71(6)$ & & \\
\hline
\end{tabular}

Symmetry codes: (i) $x, y, z+1$; (ii) $x, y+1, z$. 
(a)

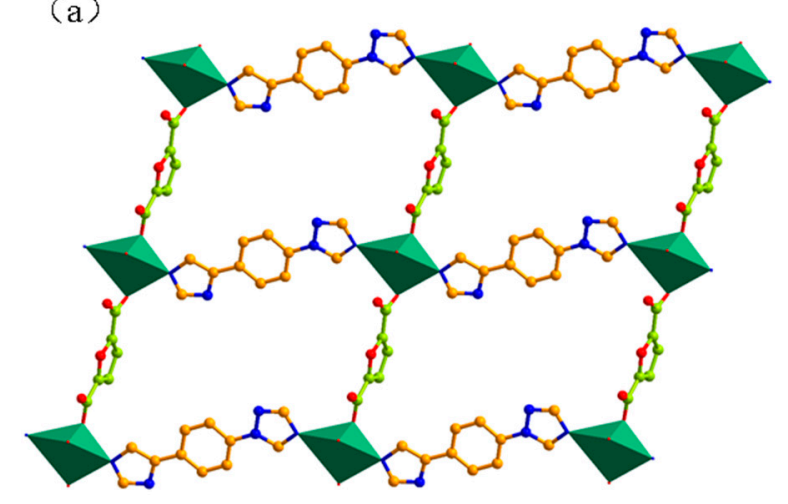

(b)

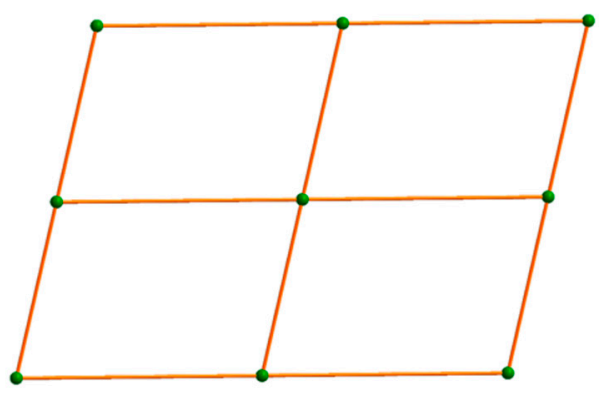

Figure 2. (a) $2 \mathrm{D}$ layer of $\left[\mathrm{Cd}(\mathrm{L})(\mathrm{frda})\left(\mathrm{H}_{2} \mathrm{O}\right)\right]$. (b) $2 \mathrm{D}$ network of $(4,4)$ topology in $\mathrm{CP} 1$.

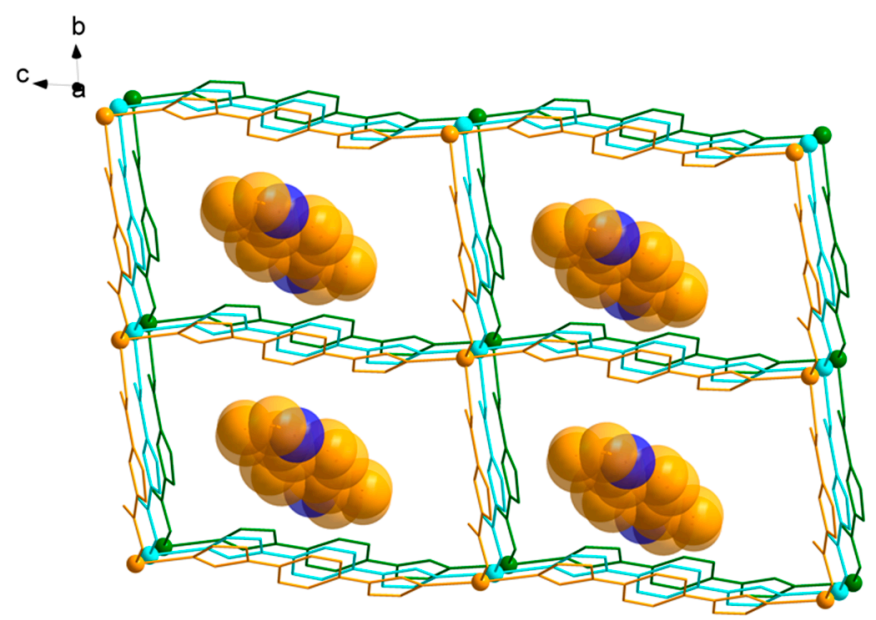

Figure 3. The 2D parallel packing layers with infinite 1D void channels embedded with uncoordinated L guest molecules.

Table 3. Hydrogen bond lengths $(\AA)$ and bond angles $\left({ }^{\circ}\right)$ for $\mathbf{1}$.

\begin{tabular}{ccccc}
\hline $\mathbf{D}-\mathbf{H} \cdots \mathbf{A}$ & $\mathbf{d}(\mathbf{D}-\mathbf{H})$ & $\mathbf{d}(\mathbf{H} \cdots \mathbf{A})$ & $\mathbf{d}(\mathbf{D} \cdots \mathbf{A})$ & $\angle$ DHA \\
\hline $\mathrm{O}(6)-\mathrm{H}(6 \mathrm{~A}) \cdots \mathrm{O}(5)^{\mathrm{a}}$ & $0.70(4)$ & $2.18(4)$ & $2.872(4)$ & $167(5)$ \\
$\mathrm{C}(6)-\mathrm{H}(6 \mathrm{~B}) \cdots \mathrm{O}(6)^{\mathrm{b}}$ & $0.79(4)$ & $1.96(4)$ & $2.738(3)$ & $169(5)$ \\
$\mathrm{C}(2)-\mathrm{H}(2) \cdots \mathrm{O}(2)^{\mathrm{c}}$ & 0.9300 & 2.3200 & $3.142(3)$ & 148.00 \\
$\mathrm{C}(4)-\mathrm{H}(4) \cdots \mathrm{N}(4)$ & 0.9300 & 2.5100 & $2.826(4)$ & 100.00 \\
$\mathrm{C}(9)-\mathrm{H}(9) \cdots \mathrm{O}(4)^{\mathrm{a}}$ & 0.9300 & 2.5400 & $3.086(3)$ & 118.00 \\
$\mathrm{C}(10)-\mathrm{H}(10) \cdots \mathrm{O}(2)^{\mathrm{c}}$ & 0.9300 & 2.2300 & $3.101(4)$ & 155.00 \\
$\mathrm{C}(11)-\mathrm{H}(11) \cdots \mathrm{O}(6)^{\mathrm{d}}$ & 0.9300 & 2.5700 & $3.410(4)$ & 151.00 \\
\hline \multicolumn{2}{l}{ Symmetry codes: ${ }^{\mathrm{a}} x, 1+y, z^{\mathrm{b}} 1-x, 1-y, 2-z^{\mathrm{c}} 2-x, 1-y, 1-z^{\mathrm{d}} 1-x, 1-y, 1-z}$.
\end{tabular}




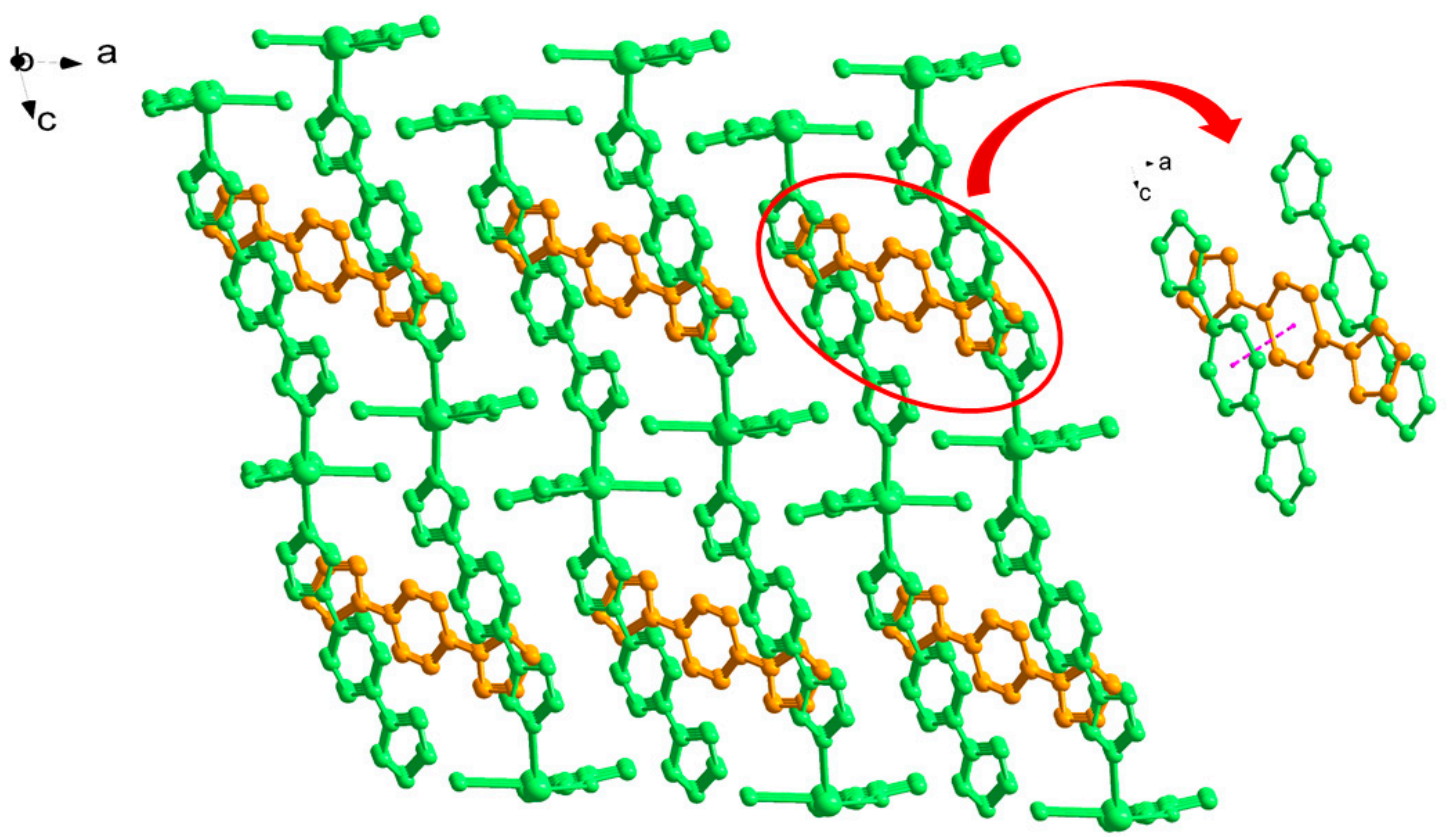

Figure 4. 3D supramolecular structure of 1 packed by $\pi \cdots \pi$ stacking interactions.

\subsection{Thermal Analysis and Powder X-Ray Diffraction Analysis}

Figure 5 shows that a $6.28 \%$ weight loss corresponds to one coordinated and one lattice water molecule in a temperature range of $185-245^{\circ} \mathrm{C}$ (calcd: $6.32 \%$ ), and the framework collapsed at about $350^{\circ} \mathrm{C}$. Powder x-ray diffraction (PXRD) data can be used to testify the purity of as-synthesized samples. Therefore, the PXRD data of CP $\mathbf{1}$ were directly collected at room temperature. The diffraction peaks of the as-synthesized 1 were consistent with the simulated PXRD patterns from the single crystal results. The result confirms that the as-synthesized crystals of 1 were phase purities as shown in Figure 6.

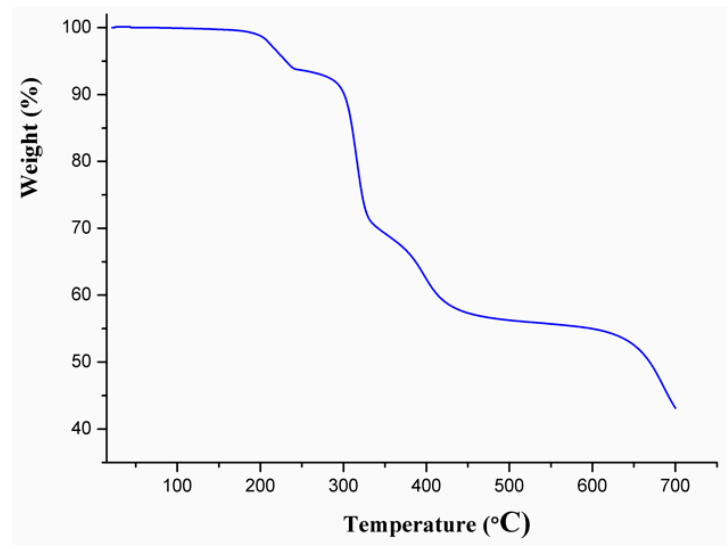

Figure 5. Thermal analysis curve of CP 1. 


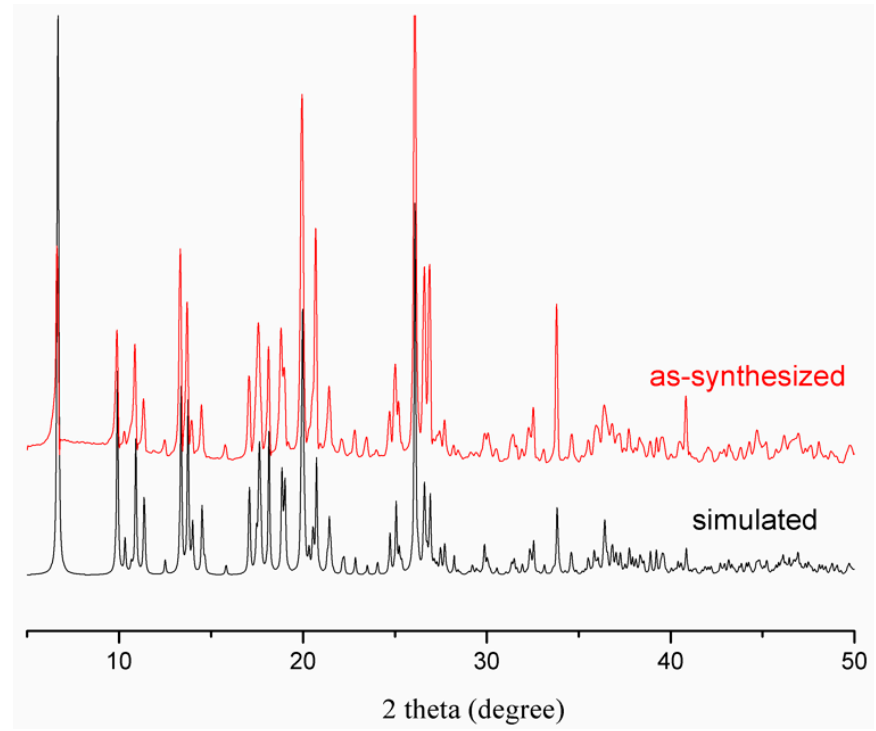

Figure 6. Simulated and experimental powder X-Ray diffraction patterns of CP $\mathbf{1}$.

\subsection{Diffuse Reflectance Spectra}

The UV-Vis spectra in the solid-state were investigated for the CP $\mathbf{1}$ together with the organic compound L (Figure 7). The CP $\mathbf{1}$ and L molecules showed the same absorption peaks ranging from 275 to $345 \mathrm{~nm}$ in the UV region, which belongs to $\pi \rightarrow \pi^{*}$ and $\mathrm{n} \rightarrow \pi^{*}$ transitions of the ligand. Furthermore, the diffuse reflectance data obtained were transformed into a Kubelka-Munk function to get their band gaps (Eg), which can be employed to evaluate the semiconductivity of the CPs. The values of Eg for 1 and L were estimated as 3.55 and $3.35 \mathrm{ev}$ (Figure 8), which can be determined by the theory of optical absorption for the direct band gap semiconductor: $(\mathrm{Ahv})^{2}=\mathrm{B}(\mathrm{h} v-\mathrm{Eg})$ [34], indicating that the as-synthesized crystalline material is an optical semiconductor [35].

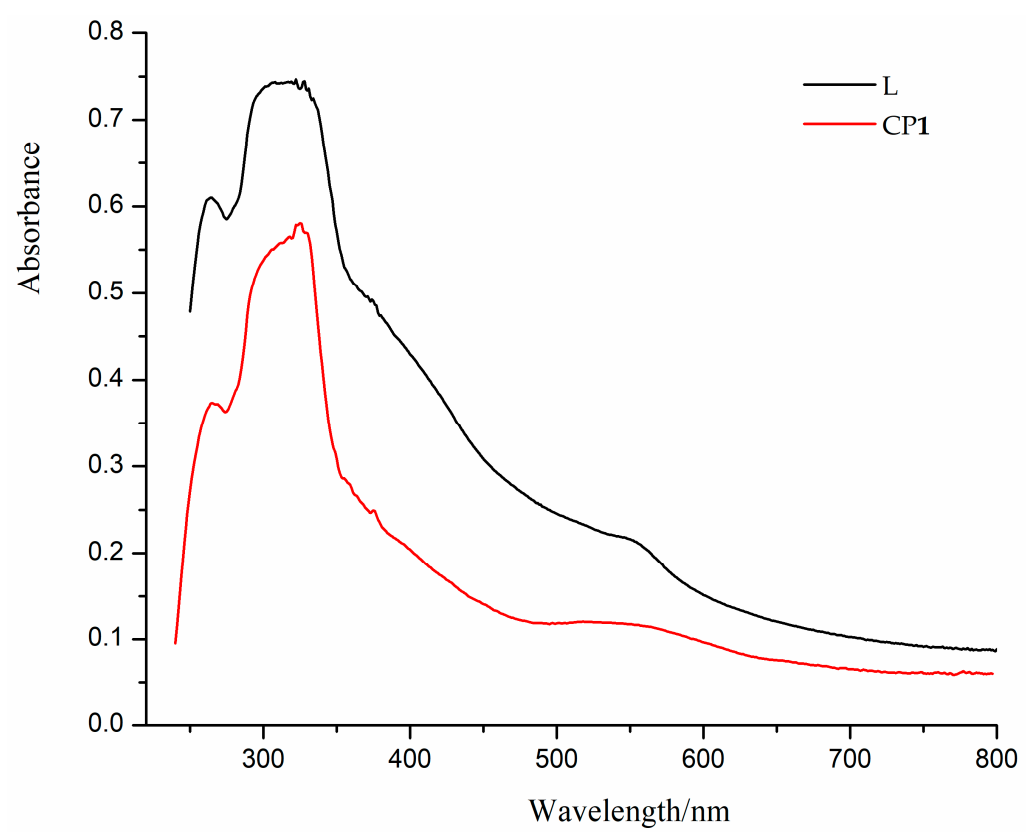

Figure 7. The UV-Vis spectra in the solid-state of the L ligand and CP 1. 


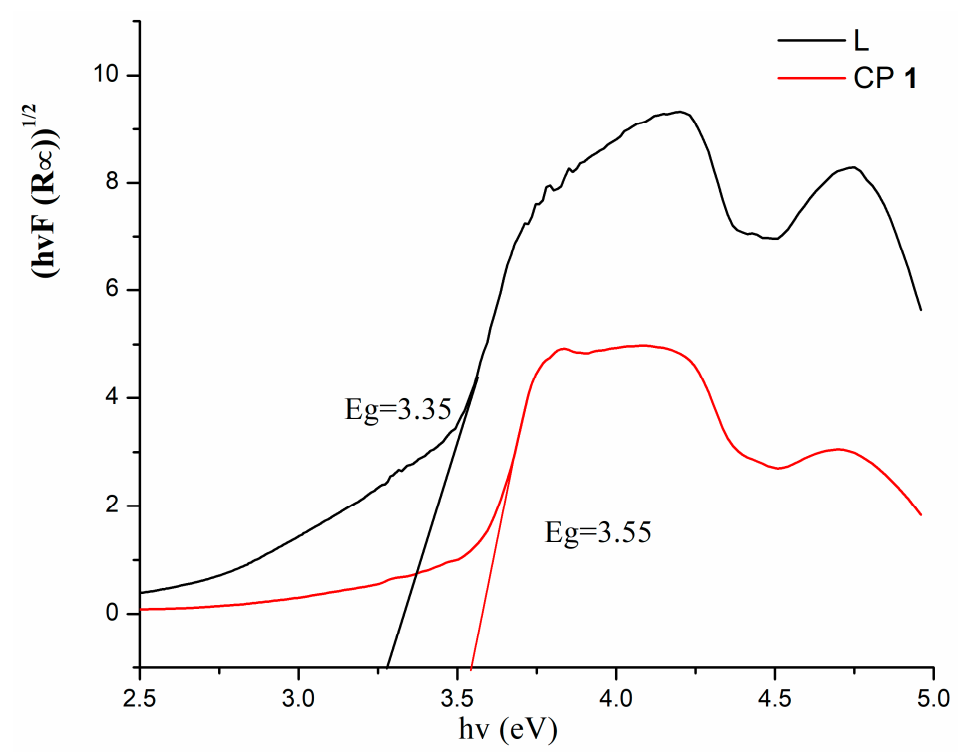

Figure 8. The band gap Eg values for L and CP 1.

\subsection{Photoluminescent Property}

Luminescent coordination polymers containing a $\mathrm{d}^{10}$ metal center and $\pi$-conjugated organic ligands can often exhibit favorable photoluminescent properties because of their tunable factors between metal and ligands [36,37]. Therefore, we carried out the relevant studies on the Cd(II) coordination polymer in the solid-state together with the L organic ligand (Figure 9). The L ligand showed no fluorescence, however, compound 1 appeared as a strong broad emission band at $415 \mathrm{~nm}$ upon excitation at $361 \mathrm{~nm}$ on complexation of the ligands with $\mathrm{Cd}(\mathrm{II})$ atoms, which may be attributable to the coordination interactions between the ligand and central metal $\mathrm{Cd}(\mathrm{II})$ atom [38].

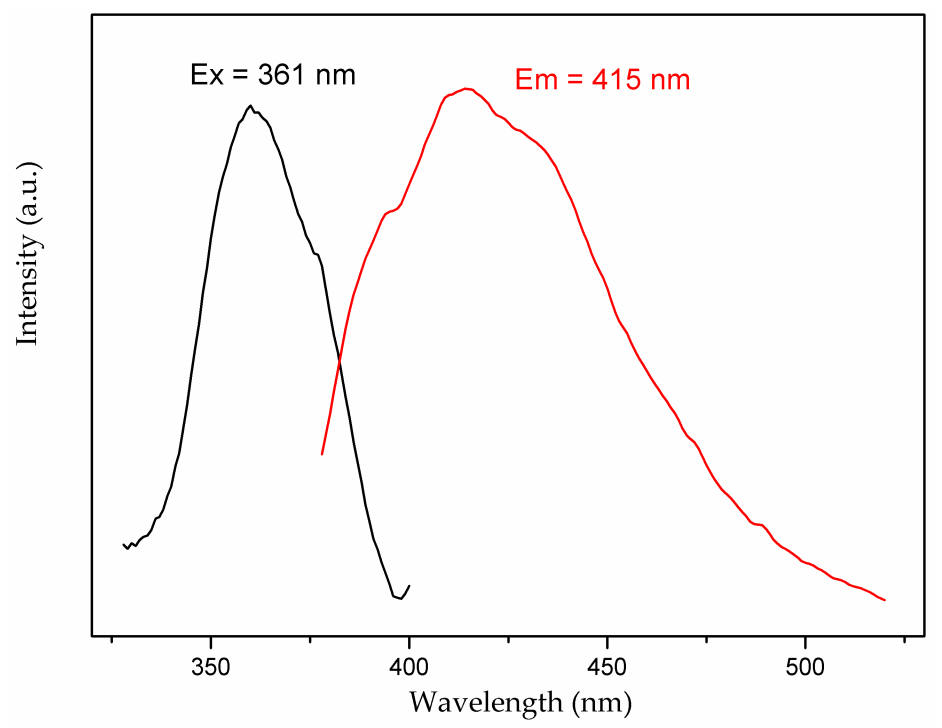

Figure 9. Photoluminescent spectra of CP 1.

The good photoluminescent property of CP 1 provided the impetus to further investigate the quantum yield (QY) and corresponding decay lifetimes. The QY value of CP 1 was $4.28 \%$ (Figure 10), similar to some reported CPs [39]. Furthermore, the luminescence decay curve was fitted by exponential function as $I(t)=A \exp (-t / \tau)$, and the luminescence lifetime of CP 1 was 48.87 ns. The value of luminescence lifetime for CP 1 was fairly shorter than a triplet state $\left(>10^{-3} \mathrm{~s}\right)$, in this context, the luminescence emission of $\mathrm{CP} \mathbf{1}$ should derive from a singlet state [40]. 

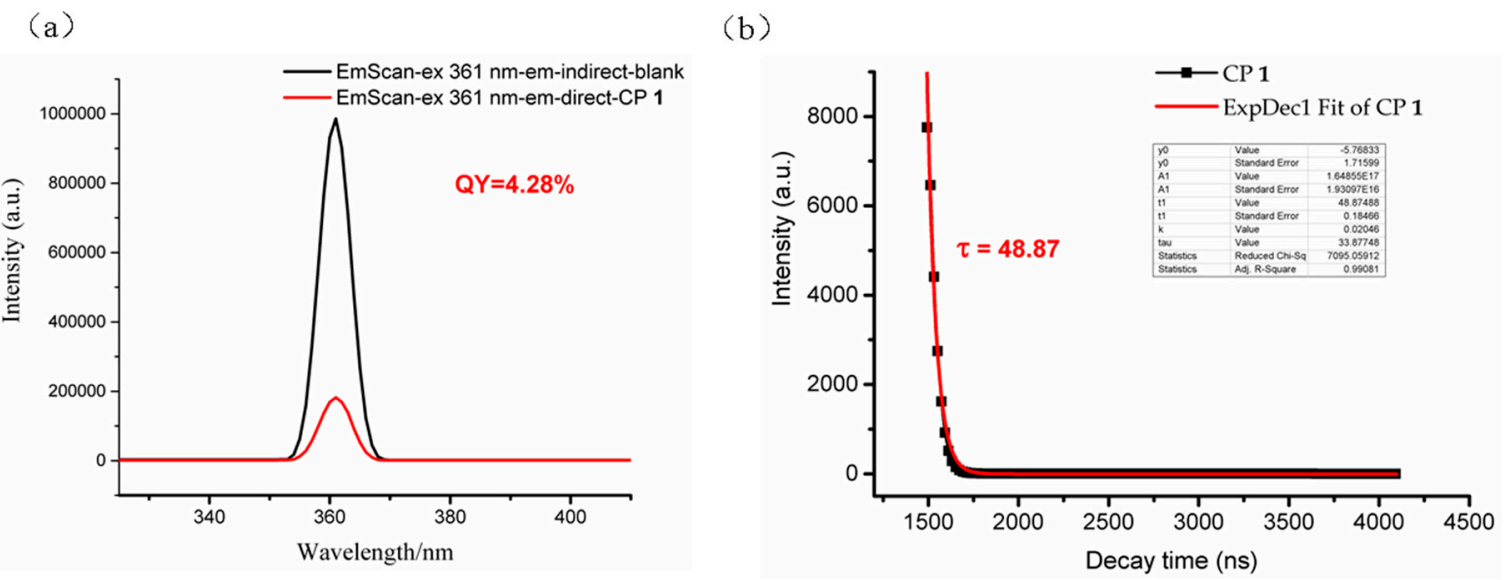

Figure 10. (a) The quantum yield curves and (b) luminescence decay curve for CP 1 (black line: experimental data; red line: fitting result).

\section{Conclusions}

In summary, a new $\mathrm{CP}$ of $\left[\mathrm{Cd}(\mathrm{L})(\mathrm{frda})\left(\mathrm{H}_{2} \mathrm{O}\right)\right] \cdot 0.5 \mathrm{~L} \cdot \mathrm{H}_{2} \mathrm{O}(\mathbf{1})$ was obtained by the reaction of $\mathrm{CdCl}_{2} \cdot 2.5 \mathrm{H}_{2} \mathrm{O}$ salt with mixed multi-N-donor and auxiliary polycarboxylate ligands. The coordination polymer was a $2 \mathrm{D}$ layer structure with a large $1 \mathrm{D}$ void filled with uncoordinated L ligands. CP 1 showed absorption peaks at $304 \mathrm{~nm}$ in the UV region with the value $\mathrm{Eg}$ of $3.55 \mathrm{eV}$. The crystalline material exhibited the maximal emission peak at $415 \mathrm{~nm}$, upon excitation at $361 \mathrm{~nm}$. Additionally, the QY and luminescence lifetime of CP 1 were $4.28 \%$ and $48.87 \mathrm{~ns}$, respectively. The study further confirmed that the mixed multi-N donor and carboxylate ligands are an effective moiety to generate desired architectures in self-assembly coordination polymers.

Supplementary Materials: The following are available online at http://www.mdpi.com/2073-4352/9/12/625/s1. Scheme S1. The synthesis method of 1-(4-(1H-imidazol-5-yl) phenyl)-1H-1,2,4-triazole.

Author Contributions: S.-S.H. and Z.-W.H. synthesized the organic molecule and CP 1, and tested the properties of CP 1. L.L. characterized the Cd(II) coordination polymer. S.-S.C. guided the project.

Funding: This research received no external funding.

Acknowledgments: This project was supported by the Youth Talent Support Program of Anhui Province (gxbjZD19) and the cooperative project (XDHX201707).

Conflicts of Interest: The authors declare no conflict of interest.

\section{References}

1. Hu, Z.C.; Deibert, B.J.; Li, J. Luminescent metal-organic frameworks for chemical sensing and explosive detection. Chem. Soc. Rev. 2014, 43, 5815-5840. [CrossRef] [PubMed]

2. Zhao, Y.; Yang, X.G.; Lu, X.M.; Yang, C.D.; Fan, N.N.; Yang, Z.T.; Wang, L.Y.; Ma, L.F. $\left\{Z_{6}\right\}$ Cluster based metal-organic framework with enhanced room-temperature phosphorescence and optoelectronic performances. Inorg. Chem. 2019, 58, 6215-6221. [CrossRef]

3. Liu, Z.Q.; Zhao, Y.; Zhang, X.D.; Kang, Y.S.; Lu, Q.Y.; Azam, M.; Al-Resayes, S.I.; Sun, W.Y. Metal-organic frameworks with 1,4-di(1H-imidazol-4-yl)benzene and varied carboxylate ligands for selectively sensing Fe(III) ions and ketone molecules. Dalton Trans. 2017, 46, 13943-13951. [CrossRef] [PubMed]

4. Yang, X.G.; Ma, L.F.; Yan, D.P. Facile synthesis of 1D organic-inorganic perovskite micro-belts with high water stability for sensing and photonic applications. Chem. Sci. 2019, 10, 4567-4572. [CrossRef] [PubMed]

5. Karmakar, A.; Samanta, P.; Desai, A.V.; Ghosh, S.K. Guest responsive metal-organic frameworks as scaffolds for separation and sensing applications. Acc. Chem. Res. 2017, 50, 2457-2469. [CrossRef]

6. Zhao, Y.; Wang, L.; Fan, N.N.; Han, M.L.; Yang, G.P.; Ma, L.F. Porous Zn(II)-based metal-organic frameworks decorated with carboxylate groups exhibiting high gas adsorption and separation of organic dyes. Cryst. Growth Des. 2018, 18, 7114-7121. [CrossRef] 
7. Zhang, K.; Xie, X.; Li, H.; Gao, J.; Nie, L.; Pan, Y.; Xie, J.; Tian, D.; Liu, W.; Fan, Q.; et al. Highly water-stable lanthanide-oxalate MOFs with remarkable proton conductivity and tunable luminescence. Adv. Mater. 2017, 29, 1701804. [CrossRef]

8. Macreadie, L.K.; Mensforth, E.J.; Babarao, R.; Konstas, K.; Telfer, S.G.; Doherty, C.M.; Tsanaktsidis, J.; Batten, S.R.; Hill, M.R. CUB-5: A contoured aliphatic pore environment in a cubic framework with potential for benzene separation applications. J. Am. Chem. Soc. 2019, 141, 3828-3832. [CrossRef]

9. Kang, Y.S.; Lu, Y.; Chen, K.; Zhao, Y.; Wang, P.; Sun, W.Y. Metal-organic frameworks with catalytic centers: From synthesis to catalytic application. Coord. Chem. Rev. 2019, 378, 262-280. [CrossRef]

10. Cook, T.R.; Stang, P.J. Recent developments in the preparation and chemistry of metallacycles and metallacages via coordination. Chem. Rev. 2015, 115, 7001. [CrossRef]

11. Li, N.; Feng, R.; Zhu, J.; Chang, Z.; Bu, X.H. Conformation versatility of ligands in coordination polymers: From structural diversity to properties and applications. Coord. Chem. Rev. 2018, 375, 558-586. [CrossRef]

12. Zhu, M.A.; Guo, X.Z.; Xiao, L.; Chen, S.S. A new Cd(II) coordination compound based on 4-(1,2,4-triazol-4yl)phenylacetic acid: Synthesis, structure and photoluminescence property. Chin. J. Struct. Chem. 2018, 37, 437-444.

13. Wu, Y.P.; Tian, J.W.; Liu, S.; Li, B.; Zhao, J.; Ma, L.F.; Li, D.S.; Lan, Y.Q.; Bu, X. Bi-microporous metal-organicframeworks with cubane $\left[\mathrm{M}_{4}(\mathrm{OH})_{4}\right](\mathrm{M}=\mathrm{Ni}, \mathrm{Co})$ clusters and pore space partition for electrocatalytic methanol oxidation reaction. Angew. Chem. Int. Ed. 2019, 58, 12185-12189. [CrossRef]

14. Zhou, Z.; Han, M.L.; Fu, H.R.; Ma, L.F.; Luo, F.; Li, D.S. Engineering design toward exploring the functional group substitution in 1D channels of Zn-organic frameworks upon nitro explosives and antibiotics detection. Dalton Trans. 2018, 47, 5359-5365. [CrossRef]

15. Zhao, X.; Bu, X.H.; Nguyen, E.T.; Zhai, Q.G.; Mao, C.Y.; Feng, P.Y. Multivariable modular design of pore space partition. J. Am. Chem. Soc. 2016, 138, 15102-15105. [CrossRef] [PubMed]

16. Guo, X.Z.; Li, J.L.; Shi, S.S.; Zhou, H.; Han, S.S.; Chen, S.S. Synthesis, structure and luminescent property of a $\mathrm{Zn}$ (II) complex with mixed multi-N donor and 2,5-dihydroxy-terephthalic acid ligands. Chin. J. Struct. chem. 2018, 37, 1117-1124.

17. Han, L.J.; Yan, W.; Chen, S.G.; Shi, Z.Z.; Zheng, H.G. Exploring the detection of metal ions by tailoring the coordination mode of V-shaped thienylpyridyl ligand in three MOFs. Inorg. Chem. 2017, 56, 2936-2940. [CrossRef]

18. Furukawa, H.; Cordova, K.E.; O'Keeffe, M.; Yaghi, O.M. The chemistry and applications of metal-organic frameworks. Science 2013, 341, 974. [CrossRef]

19. Dong, X.Y.; Si, C.D.; Fan, Y.; Hu, D.C.; Yao, X.Q.; Yang, Y.X.; Liu, J.C. Effect of N-donor ligands and metal ions on the coordination polymers based on a semirigid carboxylic acid ligand: Structures analysis, magnetic properties, and photoluminescence. Cryst. Growth Des. 2016, 16, 2062-2073. [CrossRef]

20. Roztocki, K.; Jedrzejowski, D.; Hodorowicz, M.; Senkovska, I.; Kaskel, S.; Matoga, D. Effect of linker substituent on layers arrangement, stability, and sorption of Zn-isophthalate/acylhydrazone frameworks. Cryst. Growth Des. 2018, 18, 488-497. [CrossRef]

21. Yang, G.P.; Hou, L.; Ma, L.F.; Wang, Y.Y. Investigation on the prime factors influencing the formation of entangled metal-organic frameworks. CrystEngComm 2013, 15, 2561-2578. [CrossRef]

22. Singh, R.; Bharadwaj, P.K. Coordination polymers built with a linear bis-imidazole and different dicarboxylates: Unusual entanglement and emission properties. Cryst. Growth Des. 2013, 13, 3722-3733. [CrossRef]

23. Chen, S.S.; Chen, M.; Takamizawa, S.; Wang, P.; Lv, G.C.; Sun, W.Y. Temperature dependent selective gas sorption of the microporous metal-imidazolate framework $[\mathrm{Cu}(\mathrm{L})]\left[\mathrm{H}_{2} \mathrm{~L}=1\right.$, 4-di (1H-imidazol-4-yl) benzene]. Chem. Commun. 2011, 47, 752-754. [CrossRef] [PubMed]

24. Chen, S.S.; Chen, M.; Takamizawa, S.; Wang, P.; Lv, G.C.; Sun, W.Y. Porous cobalt(II)-imidazolate supramolecular isomeric frameworks with selective gas sorption property. Chem. Commun. 2011, 47, 4902-4904. [CrossRef] [PubMed]

25. Chen, S.S.; Wang, P.; Takamizawa, S.; Okamura, T.A.; Chen, M.; Sun, W.Y. Zinc (II) and cadmium(II) metal-organic frameworks with 4-imidazole containing tripodal ligand: Sorption and anion exchange properties. Dalton Trans. 2014, 43, 6012-6020. [CrossRef] 
26. Chen, S.S.; Sheng, L.Q.; Zhao, Y.; Liu, Z.D.; Qiao, R.; Yang, S. Syntheses, structures, and properties of a series of polyazaheteroaromatic core-based $\mathrm{Zn}$ (II) coordination polymers together with carboxylate auxiliary ligands. Cryst. Growth Des. 2016, 16, 229-241. [CrossRef]

27. Chen, S.S. The roles of imidazole ligands in coordination supramolecular systems. CrystEngComm 2016, 18, 6543-6565. [CrossRef]

28. Chen, S.S.; Qiao, R.; Sheng, L.Q.; Zhao, Y.; Yang, S.; Chen, M.M.; Liu, Z.D.; Wang, D.H. Cadmium(II) and zinc(II) complexes with rigid 1-(1H-imidazol-4-yl)-3-(4H-tetrazol-5-yl)benzene and varied carboxylate ligands. CrystEngComm 2013, 15, 5713-5725. [CrossRef]

29. Ten Have, R.; Huisman, M.; Meetsma, A.; van Leusen, A.M. Novel Synthesis of 4(5)-Monosubstituted Imidazoles via Cycloaddition of Tosylmethyl Isocyanide to Aldimines. Tetrahedron 1997, 53, 11355-11368. [CrossRef]

30. Sheldrick, G.M. A short history of SHELX. Acta Cryst. 2008, A64, 112-122. [CrossRef]

31. Blatov, V.A. TOPOS, A Multipurpose Crystallochemical Analysis with the Program Package; Samara State University: Samara, Russia, 2009.

32. Chen, S.S.; Liu, Q.; Zhao, Y.; Qiao, R.; Sheng, L.Q.; Liu, Z.D.; Yang, S.; Song, C.F. New metal-organic frameworks constructed from the 4-imidazole-carboxylate ligand: Structural diversities, luminescence, and gas adsorption properties. Cryst. Growth Des. 2014, 14, 3727-3741. [CrossRef]

33. Li, J.L.; Li, W.D.; He, Z.W.; Han, S.S.; Chen, S.S. Synthesis, crystal structure, and properties of a Zn(II) coordination polymer based on a difunctional ligand containing triazolyl and carboxyl groups. Crystals 2018, 8, 424. [CrossRef]

34. Yang, Y.J.; Wang, M.J.; Zhang, K.L. A novel photoluminescent Cd(II)-organic framework exhibiting rapid and efficient multi-responsive fluorescence sensing for trace amounts of $\mathrm{Fe}^{3+}$ ions and some NACs, especially for 4-nitroaniline and 2-methyl-4-nitroaniline. J. Mater. Chem. C 2016, 4, 11404-11418. [CrossRef]

35. Su, J.; Yao, L.; Zhao, M.; Wang, H.; Zhang, Q.; Cheng, L.; Tian, Y. Structural induction effect of a zwitterion pyridiniumolate for metal-organic frameworks. Inorg. Chem. 2015, 54, 6169-6175. [CrossRef] [PubMed]

36. Sun, Y.X.; Sun, W.Y. Zinc(II)- and cadmium(II)-organic frameworks with 1-imidazole-containing and 1-imidazolecarboxylate ligands. CrystEngComm 2015, 17, 4045-4063. [CrossRef]

37. Zou, J.Y.; Gao, H.L.; Shi, W.; Cui, J.Z.; Cheng, P. Auxiliary ligand-assisted structural diversities of three metal-organic frameworks with potassium 1H-1,2,3-triazole-4,5-dicarboxylic acid: Syntheses, crystal structures and luminescence properties. CrystEngComm 2013, 15, 2682-2687. [CrossRef]

38. Zhang, L.Y.; Zhang, J.P.; Lin, Y.Y.; Chen, X.M. Syntheses, structures, and photoluminescence of three coordination polymers of cadmium dicarboxylates. Cryst. Growth Des. 2006, 6, 1684. [CrossRef]

39. Ye, R.P.; Zhang, X.; Zhai, J.Q.; Qin, Y.Y.; Zhang, L.; Yao, Y.G.; Zhang, J. N-donor ligands enhancing luminescence properties of seven $\mathrm{Zn} / \mathrm{CdIJII}) \mathrm{MOF}$ based on a large rigid $\pi$-conjugated carboxylate ligand. CrystEngComm 2015, 17, 9155-9166. [CrossRef]

40. Wang, D.Z.; Fan, J.Z.; Jia, D.Z.; Du, C.C. Zinc and cadmium complexes based on bis-(1Htetrazol5-ylmethyl/ylethyl)-amine ligands: Structures and photoluminescence properties. CrystEngComm 2016, 18, 6708-6723. [CrossRef]

(C) 2019 by the authors. Licensee MDPI, Basel, Switzerland. This article is an open access article distributed under the terms and conditions of the Creative Commons Attribution (CC BY) license (http://creativecommons.org/licenses/by/4.0/). 